\title{
GVHD risk assessment beyond current HLA evaluation
}

\author{
Sophie Paczesny ${ }^{\text {a }}$ \\ ${ }^{a}$ Indiana University School of Medicine, Indianapolis, IN 46202, USA
}

As one of the most clinically validated immunotherapies to date, allogeneic haemopoietic cell transplantation (HCT) is a potentially curative option for blood cancers via the graft-versus-leukaemia effect. However, T-cell reactivity to alloantigens in normal host tissues also gives rise to graft-versushost disease (GVHD), particularly in transplantation recipients from unrelated donors, accounting for more than $20 \%$ of deaths in patients who have a HCT. ${ }^{1}$ To limit GVHD, clinicians have been matching the patients and the unrelated donor graft the best they can using $H L A-A, H L A-B, H L A-C, H L A-D R B 1$, and HLA-DQB1.2, 3 However, this matching is not always possible, particularly for patients of non-white backgrounds who are not well represented in the donor registry. HCT from donors with one HLA mismatch followed by standard GVHD prophylaxis can be done, but is often followed by severe acute GVHD. The question of why is addressed by Effie Petersdorf and colleagues in The Lancet Haematology. ${ }^{4}$

They present results on the role of threonine (Thr; T) and methionine (Met; M) leader peptides in the non-coding exon 1 of $H L A-B$ on the risk of GVHD in 17100 HLA-matched and 1457 single HLA-B mismatched unrelated HCT recruited from the registry in which transplantations were done between Jan 1, 1988, and Dec 31, 2016, the largest multicentre, international, cohort of HCT ever reported, to our knowledge. M leader and T leader frequencies were defined in 2004742 healthy donors. These results represent a real triumph of collaboration by a team of global experts in the field.

This is the author's manuscript of the work published in final form as:

Paczesny, S. (2020). GVHD risk assessment beyond current HLA evaluation. The Lancet Haematology, 7(1), e8-e9. https://doi.org/10.1016/S2352-3026(19)30221-2 
The mature HLA class I molecule expressed on the cell surface is encoded by exons 2-7.

Sequence variation in exons 2, 3, and 4 provide the basis for the tissue type of the class I molecule, or allotype. Exon 1 of class I genes encode a separate leader peptide, which is not a structural moiety of the mature class I molecule, but can be bound and presented by class I, notably HLA-E.2, 3 HLA-A and HLA-C leader sequences are largely invariant, and encode $M$ at the -21 position. ${ }^{5} \mathrm{HLA}-\mathrm{B}$ leader sequences encode $\mathrm{M}$ or $\mathrm{T}$ at the -21 position, which differentially effect $\mathrm{T}$-cell and natural killer cell immune responses. Therefore, Petersdorf and colleagues tested the hypothesis that the dimorphic HLAB leader provides information on risks of GVHD associated with HLA-B mismatching after unrelated donor transplantation. ${ }^{4}$

First, the experts did a thorough PubMed search to establish that no previous study has examined the clinical significance of the HLA-B leader in a HCT setting, which was the case. Of note, several studies have investigated the influence of the dimorphic HLA-B leader on the course of HIV infection. ${ }^{6}$ Second, given the extreme polymorphism of HLA-B, and the high risks of GVHD associated with HLA-B mismatching, the authors evaluated the role of the HLA-B leader dimorphism in GVHD in a cohort of patients who received a transplant from a donor who was mismatched for only one HLA-B allotype and matched for the second HLA-B allotype (termed single mismatch). After determining the frequencies of $M$ and T leaders in 2004742 healthy donors, the authors showed that among single HLAmismatches, mismatches for one HLA-B increased odds for severe GVHD with leader-mismatching than with leader-matching (odds ratio [OR] 1.73, 95\% Cl 1.02-2.94; $p=0.042$ for grade $2-4$ ). They then looked at the shared HLA-B allotype and showed that an M leader had increased odds for GVHD compared with a T leader (OR 1.98, 1.39-2.81; $p=0.00014$ for grade 3-4). Race influenced outcomes of unrelated donor $\mathrm{HCT},{ }^{7}$ and was included in the multivariate analysis, which was not an independent risk factor. 
Petersdorf and colleagues show a new strategy in HLA matching to decrease the risk of GVHD, suggesting that the preferred HLA-B mismatched donor is leader-matched for the non-shared allotype and has a T leader for the shared allotype. The majority of the two million healthy donors in the BeTheMatch registry have the TT or MT genotype. What are the implications for the HCT physician? Although this study was not designed to test mechanisms through which the HLA-B leader influences GVHD, this will need to be done in future cohorts to provide enough information to use in clinical practice. When HLA-matched donors are unavailable, the HLA-B leader should be tested and added in the algorithm for decision making for donor source selection and pre-transplantation risk assessment. Leader dimorphism will differentiate high-risk HLA-B mismatches from those with lower risks to avoid deleterious HLA-B mismatches. This method will ultimately increase the pool of unrelated donors and decrease GVHD risk. In view of several recent findings in HLA as well as GVHD prophylaxis, 8,9 an updated consensus on donor selection should be established. 


\section{References}

1 Paczesny S, Hanauer D, Sun Y, Reddy P. New perspectives on the biology of acute GVHD. Bone Marrow Transplant 2010; 45: 1-11.

2 Furst D, Muller C, Vucinic V, et al. High-resolution HLA matching in hematopoietic stem cell transplantation: a retrospective collaborative analysis. Blood 2013; 122: 3220-29.

3 Howard CA, Fernandez-Vina MA, Appelbaum FR, et al. Recommendations for donor human leukocyte antigen assessment and matching for allogeneic stem cell transplantation: consensus opinion of the Blood and Marrow Transplant Clinical Trials Network (BMT CTN). Biol Blood Marrow Transplant 2015;

21: 4-7.

4 Petersdorf EW, Carrington M, O'hUigin C, et al. Role of HLA-B exon 1 in graft-versus-host disease after unrelated haemopoietic cell transplantation: a retrospective cohort study. Lancet Haematol 2019; published online Oct 25. https://doi.org/10.1016/S2352-3026(19)30208-X.

5 Petersdorf EW, Gooley TA, Malkki M, et al. HLA-C expression levels define permissible mismatches in hematopoietic cell transplantation. Blood 2014;124: 3996-4003.

6 Merino AM, Song W, He D, et al. HLA-B signal peptide polymorphism influences the rate of HIV-1 acquisition but not viral load. J Infect Dis 2012;205: 1797-805.

7 Baker KS, Davies SM, Majhail NS, et al. Race and socioeconomic status influence outcomes of unrelated donor hematopoietic cell transplantation. Biol Blood Marrow Transplant 2009; 15: 1543-54.

8 Bolanos-Meade J, Reshef R, Fraser R, et al. Three prophylaxis regimens (tacrolimus, mycophenolate mofetil, and cyclophosphamide; tacrolimus, methotrexate, and bortezomib; or tacrolimus, methotrexate, and maraviroc) versus tacrolimus and methotrexate for prevention of graftversus-host disease with haemopoietic cell transplantation with reduced-intensity conditioning: a randomised phase 
2 trial with a non-randomised contemporaneous control group (BMT CTN 1203). Lancet Haematol 2019;

6: e132-43.

9 Choi SW. A new standard treatment for prevention of GvHD after HCT? Lancet Haematol 2019; 6:

e113-14. 